\title{
Necrotizing Enterocolitis (NEC): A Devastating Disease of Prematurity
}

Parvesh M Garg ${ }^{1}$, Padma P Garg ${ }^{2}$ and Charitharth V Lal ${ }^{3^{*}}$

${ }^{1}$ Icahn school of Medicine, Elmhurst Hospital Center, Newyork, USA

${ }^{2}$ Children Medical Center, University of Texas at Southwestern Medical Center, Dallas TX, USA

${ }^{3}$ University of Alabama at Birmingham, AL, USA

"Corresponding author: Charitharth Vivek Lal, Division of Neonatal-Perinatal Medicine, Departments of Pediatrics, University of Alabama at Birmingham, USA, Tel: +2059344680; Fax: 205934-3100; E-mail: clal@peds.uab.edu

Rec date: October 05, 2015; Acc date: October 28, 2015; Pub date: November 10, 2015

Copyright: () 2015 Garg PM, et al. This is an open-access article distributed under the terms of the Creative Commons Attribution License, which permits unrestricted use, distribution, and reproduction in any medium, provided the original author and source are credited.

\begin{abstract}
Necrotizing Enterocolitis (NEC) is a common and devastating gastrointestinal emergency that primarily affects premature infants. The incidence of necrotizing enterocolitis is 6-10\% among infants with birth weight less than 1500 grams. The mortality due to NEC has not improved significantly despite advances in neonatal care and better understanding of clinical and basic sciences. The pathogenesis of NEC is not well understood and several factors such as prematurity, abnormal colonization with pathogenic bacteria, feeding practices, blood transfusion and altered intestinal barrier function may be involved. The clinical presentation of NEC could be sudden and the treatment plan could vary with the stage and type of presentation. Further research is needed to better understand the pathophysiology of NEC and, biomarkers for prediction, prevention and treatment need to be developed. Further clinical trials are needed to determine prevention and treatment modalities for this devastating disease.
\end{abstract}

Keywords: Necrotising enterocolitis; Prematurity; NEC

\section{Introduction}

Necrotizing Enterocolitis (NEC) is a common and devastating gastrointestinal emergency that primarily affects premature infants in neonatal intensive care units worldwide. Despite major advances in the medical care of premature infants, the etiology of NEC is still incompletely understood, and has become a research priority [1].

\section{Epidemiology}

The incidence of NEC is 6 to $10 \%$ among infants with birth weight less than $1500 \mathrm{~g}$ and varies among different US centers and across the world $[2,3]$. The disease is primarily seen in premature infants, however some term infants may also develop NEC. NEC in term infants is usually associated with predisposing factors such as asphyxia, polycythemia, congenital heart disease and congenital gastro-intestinal anomalies, and the disease pathophysiology in term infants is different from that in preterm infants. In the long term, survivors of NEC are at an increased risk of neurodevelopmental delays [4,5]. Due to technological advances in the recent years, the mortality in preterm infants due to pulmonary causes, infection and central nervous system injury have been on the decline but NEC related deaths have steadily increased [6]. Over the past three decades, the NEC related mortality (up to $40 \%$ ) has not improved significantly despite advances in neonatal care and better understanding of clinical and basic sciences [4]. The annual cost of managing NEC infants in United States is between $\$ 500$ million and $\$ 1$ billion. The mean cost of care over 5 year's period for a child with short bowel syndrome has been estimated to be around $\$ 1.5$ million [7].

\begin{tabular}{|c|c|c|c|}
\hline Staging & Common Clinical findings & Common Radiological findings & Common Gastrointestinal findings \\
\hline Stage 1 & $\begin{array}{l}\text { Apnea and bradycardia, temperature } \\
\text { instability }\end{array}$ & Normal gas pattern or mild ileus & $\begin{array}{l}\text { Gastric residuals, occult blood in stool, mild abdominal } \\
\text { distention }\end{array}$ \\
\hline Stage II & $\begin{array}{l}\text { Apnea and bradycardia, temperature } \\
\text { instability, Thrombocytopenia and mild } \\
\text { metabolic acidosis }\end{array}$ & $\begin{array}{l}\text { lleus gas pattern with one or more } \\
\text { dialated loops and pneumatosis, ascites, } \\
\text { portal-venous gas }\end{array}$ & $\begin{array}{l}\text { Grossly bloody stools, prominent abdominal distention, } \\
\text { absent bowel sounds, abdominal wall edema with palpable } \\
\text { loops and tenderness }\end{array}$ \\
\hline Stage III & $\begin{array}{l}\text { Worsening metabolic acidosis, oliguria, } \\
\text { hypotension, coagulopathy, shock, } \\
\text { deterioration in laboratory values and vital } \\
\text { signs }\end{array}$ & $\begin{array}{l}\text { Prominent bowel loops, worsening } \\
\text { ascites, Pneumoperitoneum }\end{array}$ & $\begin{array}{l}\text { Worsening wall edema, erythema and induration, } \\
\text { Perforated bowel }\end{array}$ \\
\hline
\end{tabular}

Table 1: NEC staging.

\section{Pathogenesis}

Prematurity: Prematurity is the single most important risk factor for NEC. $90 \%$ of the cases occur in very low birth weight infants although the exact underlying mechanisms responsible for NEC, still remain unknown. Animal and human studies have identified alterations in the intestinal host immune [8] defense [9], bacterial colonization [10], blood flow regulation [11], motility [12] and inflammatory response 
$[13,14]$ to be responsible for gut inflammation and injury. Low gastric acid secretion in preterm infants and its inhibition by use of $\mathrm{H} 2$ blockers has also been linked to development of NEC [8].

Role of feeding: Delayed introduction of enteral feeding has been associated with the development of NEC. Total parental nutrition leads to intestinal mucosal atrophy and increases the risk of NEC [15] and recent data suggests that early enteral feeding may reduce the risk of NEC $[16,17]$. Preterm infants given exclusive diets of preterm formula had a significantly greater duration of parenteral nutrition, and higher incidence of surgical NEC compared to infants who were administered human milk $[18,19]$. In preterm and low birth weight infants, feeding with formula milk compared with donor breast milk resulted in a higher rate of short-term growth but also a higher risk of developing NEC [20]. Larger randomized control trials are currently underway to provide insights into the long term outcomes of donor human milk on preterm infants.

Role of inflammation and immunological factors: Inflammatory and immunological factors play a vital role in the pathogenesis of NEC. A large body of data suggests that imbalance between Toll like receptors 4 (TLR) and TLR 9 is responsible for development of the disease. TLR4 activation leads to apoptosis and effects enterocyte proliferation and migration [21]. Some studies have implicated the role of Paneth cells (PCs) in NEC. Cooperation between intestinal stem cells and Paneth cells in a niche localized to the crypts is essential for normal renewal of intestinal surface. Moreover, after the intestine is seriously damaged by infection or other insults, Paneth cell dysfunction leads to NEC [22].

Intestinal macrophages progressively acquire a non-inflammatory profile during gestational development. Transforming Growth Factor $\beta$ (TGF- $\beta$ ), particularly the TGF- $\beta 2$ isoform, suppresses macrophage inflammatory responses in the developing intestine and protects against inflammatory mucosal injury. Enterally administered TGF- $\beta 2$ protects mice from experimental NEC like injury [23]. The infants who developed NEC have low levels of circulating TGF- $\beta$ on postnatal day one as compared to non-NEC controls [24]. Data suggests there are low levels of TGF- $\beta$ and increased level of in the tumor necrosis factor and IL-1beta in surgically resected human NEC tissue. Some studies suggest that an increased IL-8 secretion by fetal enterocytes may trigger an excessive inflammatory response responsible for intestinal injury $[25,26]$.

\begin{tabular}{|c|c|c|}
\hline & NEC & SIP \\
\hline Age & $>2$ weeks & First 2 weeks \\
\hline Bloody stools & Uncommon & No \\
\hline Ileus & Yes & Variable \\
\hline Pneumoperitoneum & In advanced NEC & Always \\
\hline $\begin{array}{l}\text { Pneumatosis } \\
\text { Intestinalis }\end{array}$ & Yes & No \\
\hline $\begin{array}{l}\text { Inflammatory } \\
\text { response }\end{array}$ & Yes & Variable/No \\
\hline Prognosis & $\begin{array}{l}\text { Variable-Worse if surgical } \\
\text { NEC }\end{array}$ & $\begin{array}{l}\text { Relatively better than } \\
\text { NEC }\end{array}$ \\
\hline
\end{tabular}

Table 2: Difference between NEC and SIP in preterm infants.

Role of blood transfusion: In the recent years, packed red blood cell (PRBC) transfusions have been associated with onset of NEC.
Transfusion associated NEC (TANEC) has been reported in multiple studies, although the causality between PRBC transfusion and NEC has not yet been established [27-29]. Majority of very low birth weight (VLBW) infants require one or more PRBC transfusions during their stay in the neonatal intensive care unit (NICU [30], thus making TANEC, an important entity to consider. Some studies although show contradictory results and indicates that blood transfusions are not a risk factor for NEC [31].

Preterm splanchnic tissue undergoes a large degree of tissue oxygenation variability during $\mathrm{RBC}$ transfusions and does not change with increasing maturity. This combined with lower average tissue oxygenation, may explain susceptibility of the preterm gut to transfusion- related acute gut injury (TRAGI) [32]. PRBC transfusion in enterally fed preterm lambs promotes mesenteric vasoconstriction and impairs vasorelaxation by reducing mesenteric arterial endothelial NO synthase (eNOS) [33]. In addition stored PRBC may be less deformable and may not pass well through the gut microcirculation.

Feeding during blood transfusion is controversial and different neonatal units have different practices [34]. Some investigators have suggested that withholding feeds during transfusion could prevent NEC [35], and few believe that the infant remain on small volume feeds during transfusion. Overall, the current body of literature suggests that transfusion may be 'associated' with severe form of NEC (stage 3, Surgical NEC) in the extremely premature (less than 28 weeks), and low birth weight infants. In our view, TANEC may represent a different subset of NEC, and more evidence is needed before making any major practice changes.

Role of intestinal barrier: Experimental NEC been has associated with disruption of the intestinal barrier. Epithelial growth factor helps in intestinal integrity at the site of injury by accelerating goblet cell maturation and mucin production and normalizing expression of tight junction proteins [36]. The administration of probiotics (B. bifidum) protects against NEC in the neonatal rat model. This protective effect was associated with reduction of inflammatory reaction in the ileum, regulation of main components of mucus layer, and improvement of intestinal integrity $[37,38]$.

Intestinal barrier function can be assessed by urinary measurement of Biomarkers such as intestinal fatty acid-binding protein (I-FABP) and fecal measurement of calprotectin $[39,40]$ and optimising intestinal barrier function may be important in preventing NEC [41].

Altered microbial colonization: 'Microbiota' can be defined as the microbes associated with a particular context. Unlike traditional microbiological approaches that aim to identify individual pathogens, microbiome analysis characterizes all of the bacterial species present both in terms of their identities and relative abundance [42]. Technological advances have revolutionized the efforts to understand the role played by microbes in disease physiology in recent years. High-throughput sequencing of 16S rRNA gene generated from bacteria-containing samples yields a large number of short sequences that can be subsequently aligned and sorted according to a predefined level of homology. Then, these are classified according to publicly available taxonomic databases $[43,44]$. Recent evidence suggests, that alteration in gut microbiome may contribute to intestinal injury and NEC in preterm infants. Hospitalized premature infants intestines are colonized with less diverse bacterial species as compared to healthy breast fed infants which are colonized predominantly with anaerobic species of Bifidobacteria and Lactobacilli $[45,46]$. Data suggests that preterm infants are colonized with less diverse bacterial population, 
Page 3 of 6

more predominantly with Proteobacterial species and less Clostridia species $[10,47,48]$. Nevertheless, a recent study indicates that no consistent pattern in the microbiome composition was seen in infants who developed NEC and strains colonizing each baby were typically distinct [49]. In animal models, investigators have examined the correlation of mucosa-associated microbiome abundance with the severity of intestinal injury, and found that animals developing NEC have higher quantities of bacterial micro colonies along the villi and in the intestinal crypts compared to healthy animals [50]. Another recent study, supports this hypothesis and indicates that depth of bacterial invasion in resected intestinal tissue predicts mortality in surgical NEC [51].

The different etiological factors have been summarized in Figure 1.

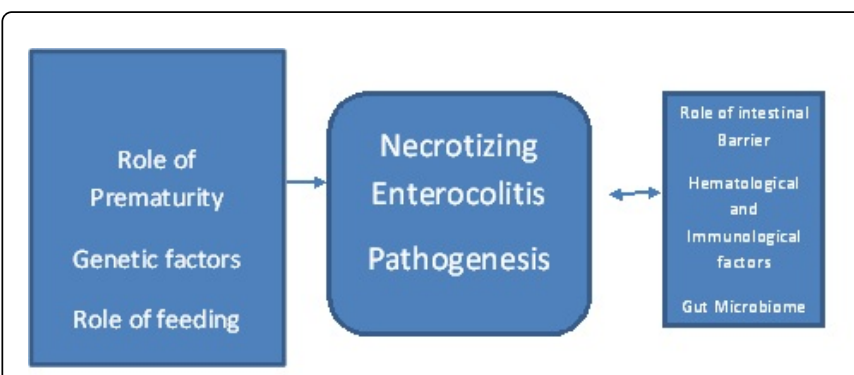

Figure 1: NEC pathogenesis.

The study of systems biology of NEC is a fascinating new field of research and includes employing microbiomics, metabolomics, transcriptomics and other 'OMIC' strategies. As our understanding about host-microbiome interactions and the development of NEC moves forward, we must be mindful of an extremely complex ecology that houses 10 times more cells and 100 times more genes than the human host. Continued awareness of underlying processes and recognition that associations are not the same as mechanistic explanations, remain essential [52].

\section{Clinical Presentation}

The clinical presentation of NEC may be extremely variable. NEC may present with symptoms of increased gastric residuals, feeding intolerance, bradycardia, tachycardia, apnea, vomiting, abdominal distension, blood in stools, abdominal discoloration, metabolic acidosis and if severe, with the clinical picture of shock and sepsis. The hematological abnormalities seen in NEC are anemia, thrombocytopenia, disseminated intravascular coagulopathy, significant decrease in the number of absolute monocyte count, increased or decreased level of neutrophils, eosinophilia [53]. A recent study has shown that NEC leads to renal dysfunction, metabolic acidosis through disruption of tight junction proteins [54,55].

\section{Diagnosis}

Clinical and radiological features are primarily employed for the diagnosis of NEC. Bell and colleagues suggested a classification scheme that differentiates suspected NEC (stage 1) from proven (stage 2) and advanced NEC (stage 3). Stage 1 presents with nonspecific symptoms and stage 2 is definitive NEC with radiological evidence of pneumatosis intestinalis and/or portal venous gas. Stage 3 NEC is presents with systemic signs with radiographic evidence of intestinal perforation (pneumoperitoneum) [56]. The Bell's staging is shown in Table 1.

A very close differential of NEC is spontaneous intestinal perforation (SIP) as shown in Table 2 which is usually seen first few days of life in extremely preterm infants. In SIP, the inflammatory response is less marked as compared to NEC, and both diseases have completely different pathophysiological mechanisms [57]. Indomethacin and early use of steroids have been shown to increase the incidence of SIP $[58,59]$.

Patients with NEC stage 1 and 2 are usually managed conservatively, while infants with stage 3 NEC may require surgical intervention, which may include laparotomy or a peritoneal drain placement. A multicenter randomized trial comparing outcomes of primary peritoneal drainage with laparotomy in preterm infants with perforated NEC found no significant differences and hence, further larger studies are underway [60].

Recent evidence suggests that, fecal volatile organic compounds (VOCs) analysis by an electronic nose (eNose) may allow for an early detection of NEC [61]. Due to low specificity, immunologic and hematological abnormalities are likely to be less useful as diagnostic tests and may be a "early-warning" systems that indicate a need for clinical monitoring and/or imaging [53,62].

Liberal use of antibiotics in premature infants is associated with an increased incidence of NEC [71]. With the mounting evidence regarding the role of the gut microbiome dysbiosis in NEC pathogenesis, excessive use of antibiotics and $\mathrm{H} 2$ blocker in preterm infants, should be discouraged. Antibiotic stewardship in preterm infants is the need of the hour (Table 3).

\begin{tabular}{|l|}
\hline Risk factors for necrotizing enterocolitis \\
\hline Prematurity [8-14] \\
\hline Role of inflammation /immunological fcators [21-26] \\
\hline Role of feeding [15-20] \\
\hline Role of intestinal barrier [36-41] \\
\hline Role of hematological factors [27-35] \\
\hline Gut microbiome [42-51] \\
\hline Possible prevention stratergies : \\
\hline Breast milk [17,63] \\
\hline Donor breast milk \\
\hline Standardized feeding protocol [64] \\
\hline Probiotics [ 65-67] \\
\hline Prebiotics [68,69] \\
\hline Synbiotics [70] \\
\hline Minimal use of antibiotics [71] \\
\hline
\end{tabular}

Table 3: NEC: Summary of risk factors and prevention stratergies. 


\section{Prevention}

Breast milk contains multiple factors, which may improve the preterm intestinal host defenses, and early human milk feedings have been shown to be protective against NEC [17,63]. Donor breast milk has also shown promise in the prevention of NEC compared to formula feeds, although larger long term studies are still underway. In addition, standardized feeding protocols may help in decreasing the incidence of NEC [64]. Although probiotics may decrease the incidence of NEC, they have not been shown to change NEC related mortality [65-67]. Most reports support routine administration of probiotics as safe and efficacious in the preterm population, however the long-term effects such as neurodevelopmental outcomes and growth patterns, are yet to be investigated. The FDA has not yet approved the routine use of probiotics in preterm infant and further trials are needed before their routine usage. Some data suggests that supplementing feeds with prebiotics such as oligosaccharides, which increases the growth of beneficial intestinal flora may be beneficial $[68,69]$. Very few studies have examined the effects of synbiotics (combination of prebiotic and probiotic preparations) in the preterm population. Although the use a symbiotic combination (Lactobacilli + Fructooligosaccharides + Bifidobacteria) resulted in an increased stool content of Bifidobacteria in preterm infants, no differences in stool short chain fatty acids content, weight gain, or incidence of NEC were observed when compared to placebo [70].

\section{Future Directions}

The understanding of cellular processes in the pathogenesis of NEC is still in its nascent phases. Hence, more translational and basic science studies are required to further enhance our understanding about innate immune, barrier function and inflammatory response in the premature gut. Sensitive and specific biomarkers using newer systems biology approaches need to be developed, for the prediction, early diagnosis and progression of NEC. Moreover, well-designed prospective clinical trials with long term outcome data are needed for the prevention and treatment of this devastating disease.

\section{References}

1. Grave GD, Nelson SA, Walker WA, Moss RL, Dvorak B, et al. (2007) New therapies and preventive approaches for necrotizing enterocolitis: report of a research planning workshop. Pediatr Res 62: 510-514.

2. Holman RC, Stoll BJ, Curns AT, Yorita KL, Steiner CA, et al. (2006) Necrotising enterocolitis hospitalisations among neonates in the United States. Paediatr Perinat Epidemiol 20: 498-506.

3. Horbar JD, Badger GJ, Carpenter JH, Fanaroff AA, Kilpatrick S, et al. (2002) Trends in mortality and morbidity for very low birth weight infants, 1991-1999. Pediatrics 110: 143-151.

4. Hintz SR, Kendrick DE, Stoll BJ, Vohr BR, Fanaroff AA, et al. (2005) Neurodevelopmental and growth outcomes of extremely low birth weight infants after necrotizing enterocolitis. Pediatrics 115: 696-703.

5. Salhab WA, Perlman JM, Silver L, Sue Broyles R (2004) Necrotizing enterocolitis and neurodevelopmental outcome in extremely low birth weight infants $<1000 \mathrm{~g}$. J Perinatol 24: 534-540.

6. Patel RM, Kandefer S, Walsh MC, Bell EF, Carlo WA, et al. (2015) Causes and timing of death in extremely premature infants from 2000 through 2011. N Engl J Med 372: 331-340.

7. Spencer AU, Kovacevich D, McKinney-Barnett M, Hair D, Canham J, et al. (2008) Pediatric short-bowel syndrome: the cost of comprehensive care. Am J Clin Nutr 88: 1552-1559.
8. Guillet R, Stoll BJ, Cotten CM, Gantz M, McDonald S, et al. (2006) Association of H2-blocker therapy and higher incidence of necrotizing enterocolitis in very low birth weight infants. Pediatrics 117: e137-142.

9. Walker WA (2000) Role of nutrients and bacterial colonization in the development of intestinal host defense. J Pediatr Gastroenterol Nutr 30 Suppl 2: S2-7.

10. Wang Y, Hoenig JD, Malin KJ, Qamar S, Petrof EO, et al. (2009) 16S rRNA gene-based analysis of fecal microbiota from preterm infants with and without necrotizing enterocolitis. ISME J 3: 944-954.

11. Nowicki PT (1998) Effects of sustained flow reduction on postnatal intestinal circulation. Am J Physiol 275: G758-768.

12. Berseth CL (1994) Gut motility and the pathogenesis of necrotizing enterocolitis. Clin Perinatol 21: 263-270.

13. Dvorak B, Khailova L, Clark JA, Hosseini DM, Arganbright KM, et al. (2008) Comparison of epidermal growth factor and heparin-ᄀ-binding epidermal growth factor-like growth factor for prevention of experimental necrotizing enterocolitis. J Pediatr Gastroenterol Nutr 47: 11-18.

14. Nanthakumar N, Meng D, Goldstein AM, Zhu W, Lu L, et al. (2011) The mechanism of excessive intestinal inflammation in necrotizing enterocolitis: an immature innate immune response. PLoS One 6: e17776.

15. Niinikoski H, Stoll B, Guan X, Kansagra K, Lambert BD, et al. (2004) Onset of small intestinal atrophy is associated with reduced intestinal blood flow in TPN-fed neonatal piglets. J Nutr 134: 1467-1474.

16. Ehrenkranz RA, Das A, Wrage LA, Poindexter BB, Higgins RD, et al. (2011) Early nutrition mediates the influence of severity of illness on extremely LBW infants. Pediatr Res 69: 522-529.

17. Sisk PM, Lovelady CA, Dillard RG, Gruber KJ, O'Shea TM (2007) Early human milk feeding is associated with a lower risk of necrotizing enterocolitis in very low birth weight infants. J Perinatol 27: 428-433.

18. Cristofalo EA, Schanler RJ, Blanco CL, Sullivan S, Trawoeger R, et al. (2013) Randomized trial of exclusive human milk versus preterm formula diets in extremely premature infants. J Pediatr 163: 1592-1595.

19. Sullivan S, Schanler RJ, Kim JH, Patel AL, Trawöger R, et al. (2010) An exclusively human milk-based diet is associated with a lower rate of necrotizing enterocolitis than a diet of human milk and bovine milkbased products. J Pediatr 156: 562-567.

20. Quigley M, McGuire (2014) Formula versus donor breast milk for feeding preterm or low birth weight infants. Cochrane Database Syst Rev 4: 2971-2972.

21. Fusunyan RD, Nanthakumar NN, Baldeon ME, Walker WA (2001) Evidence for an innate immune response in the immature human intestine: toll-like receptors on fetal enterocytes. Pediatr Res 49: 589-593.

22. McElroy SJ, Underwood MA, Sherman MP (2013) Paneth cells and necrotizing enterocolitis: a novel hypothesis for disease pathogenesis. Neonatology 103: 10-20.

23. Maheshwari A, Kelly DR, Nicola T, Ambalavanan N, Jain SK, et al.(2011) TGF-ᄀ-beta2 suppresses macrophage cytokine production and mucosal inflammatory responses in the developing intestine. Gastroenterology 140: 242-253.

24. Maheshwari A, Schelonka RL, Dimmitt RA, Carlo WA, MunozHernandez B, et al. (2014) Cytokines associated with necrotizing enterocolitis in extremely-low-birth-weight infants. Pediatr Res 76: 100-108.

25. Nanthakumar NN, Fusunyan RD, Sanderson I, Walker WA (2000) Inflammation in the developing human intestine: A possible pathophysiologic contribution to necrotizing enterocolitis. Proc Natl Acad Sci U S A 97: 6043-6048.

26. Martin CR, Walker WA (2006) Intestinal immune defences and the inflammatory response in necrotising enterocolitis. Semin Fetal Neonatal Med 11: 369-377.

27. Mohamed A, Shah PS (2012) Transfusion associated necrotizing enterocolitis: a meta-analysis of observational data. Pediatrics 129: 529-540. 
28. Paul DA, Mackley A, Novitsky A, Zhao Y, Brooks A, et al. (2011) Increased odds of necrotizing enterocolitis after transfusion of red blood cells in premature infants. Pediatrics 127: 635-641.

29. Christensen RD, Lambert DK, Henry E, Wiedmeier SE, Snow GL, et al. (2010) Is "transfusion-associated necrotizing enterocolitis" an authentic pathogenic entity? Transfusion 50: 1106-1112.

30. Strauss RG (1997) Practical issues in neonatal transfusion practice. Am J Clin Pathol 107: S57-63.

31. Sharma R, Kraemer DF, Torrazza RM, Mai V, Neu J, et al. (2014) Packed red blood cell transfusion is not associated with increased risk of necrotizing enterocolitis in premature infants. J Perinatol 34: 858-862.

32. Bailey, Hendricks Munoz, Mally (2015) Variability in splanchnic tissue oxygenation during preterm red blood cell transfusion given for symptomatic anaemia may reveal a potential mechanism of transfusionᄀ-related acute gut injury. Blood Transfus 3: 429-434.

33. Nair J, Gugino SF, Nielsen LC, Allen C, Russell JA, et al. (2013) Packed red cell transfusions alter mesenteric arterial reactivity and nitric oxide pathway in preterm lambs. Pediatr Res 74: 652-657.

34. Parige R, Turner C, Sundaram S, Power S (2014) Enteral feeding during packed red blood cell transfusion in English neonatal units. Arch Dis Child Fetal Neonatal Ed 99: F173.

35. El-Dib M, Narang S, Lee E, Massaro AN, Aly H (2011) Red blood cell transfusion, feeding and necrotizing enterocolitis in preterm infants. J Perinatol 31: 183-187.

36. Clark JA, Doelle SM, Halpern MD, Saunders TA, Holubec H, et al. (2006) Intestinal barrier failure during experimental necrotizing enterocolitis: protective effect of EGF treatment. Am J Physiol Gastrointest Liver Physiol 291: G938-949.

37. Khailova L, Dvorak K, Arganbright KM, Halpern MD, Kinouchi T, et al. (2009) Bifidobacterium bifidum improves intestinal integrity in a rat model of necrotizing enterocolitis. Am J Physiol Gastrointest Liver Physiol 297: G940-949.

38. Bergmann KR, Liu SX, Tian R, Kushnir A, Turner JR et al. (2013) Bifidobacteria stabilize claudins at tight junctions and prevent intestinal barrier dysfunction in mouse necrotizing enterocolitis. Am J Pathol 182: 1595-1606.

39. Reisinger KW, Van der Zee DC, Brouwers HA, Kramer BW, van Heurn LW, et al. (2012) Noninvasive measurement of fecal calprotectin and serum amyloid A combined with intestinal fatty acid-binding protein in necrotizing enterocolitis. J Pediatr Surg 47: 1640-1645.

40. Evennett NJ, Hall NJ, Pierro A, Eaton S (2010) Urinary intestinal fatty acid-binding protein concentration predicts extent of disease in necrotizing enterocolitis. J Pediatr Surg 45: 735-740.

41. Halpern MD, Denning PW (2015) The role of intestinal epithelial barrier function in the development of NEC. Tissue Barriers 3: e1000707.

42. Rogers GB, Shaw D, Marsh RL, Carroll MP, Serisier DJ, et al. (2014) Respiratory microbiota: addressing clinical questions, informing clinical practice. Thorax 1: 70-81.

43. Liu Z, DeSantis TZ, Andersen GL, Knight R (2008) Accurate taxonomy assignments from $16 \mathrm{~S}$ rRNA sequences produced by highly parallel pyrosequencers. Nucleic Acids Res 36: e120.

44. Schloss PD, Westcott SL, Ryabin T, Hall JR, Hartmann M, et al. (2009) Introducing mothur: open-source, platform-independent, communitysupported software for describing and comparing microbial communities. Appl Environ Microbiol 75: 7537-7541.

45. Gewolb IH, Schwalbe RS, Taciak VL, Harrison TS, Panigrahi P (1999) Stool microflora in extremely low birthweight infants. Arch Dis Child Fetal Neonatal Ed 80: F167-173.

46. Jacquot A, Neveu D, Aujoulat F, Mercier G, Marchandin H, et al. (2011) Dynamics and clinical evolution of bacterial gut microflora in extremely premature patients. J Pediatr 158: 390-396.

47. Mai V, Young CM, Ukhanova M, Wang X, Sun Y, et al. (2011) Fecal microbiota in premature infants prior to necrotizing enterocolitis. PLoS One 6: e20647.
48. McMurtry VE, Gupta RW, Tran L, Blanchard EE, Penn D, et al. (2015) Bacterial diversity and Clostridia abundance decrease with increasing severity of necrotizing enterocolitis. Microbiome 3: 11.

49. Raveh-Sadka T, Thomas BC, Singh A, Firek B, Brooks B, et al. (2015) Gut bacteria are rarely shared by co- $\neg$-hospitalized premature infants, regardless of necrotizing enterocolitis development. Elife 4-5.

50. Støy AC, Mølbak L, Delègue CL, Thymann T, Sangild PT, et al. (2015) Necrotizing Enterocolitis in Preterm Pigs Is Associated with Increased Density of Intestinal Mucosa-Associated Bacteria Including Clostridium perfringens. Neonatology 108: 188-195.

51. Remon JI, Amin SC, Mehendale SR, Rao R, et al. (2015) Depth of bacterial invasion in resected intestinal tissue predicts mortality in surgical necrotizing enterocolitis. J Perinatol 35: 755-762.

52. McElroy SJ (2015) The Role of Bacteria in Necrotizing Enterocolitis: Understanding the Forest for the Trees. Neonatology 108: 196-197.

53. Maheshwari A (2015) Immunologic and Hematological Abnormalities in Necrotizing Enterocolitis. Clin Perinatol 42: 567-585.

54. Garg PM, Tatum R, Ravisankar S, Shekhawat PS, Chen YH (2015) Necrotizing enterocolitis in a mouse model leads to widespread renal inflammation, acute kidney injury, and disruption of renal tight junction proteins. Pediatric research 146-147.

55. Garg PM, Tatum R, Ravisankar S, Shekhawat PS, Chen YH, et al. (2014) Necrotizing enterocolitis leads to renal abnormality mediated through tight junction proteins (60.8). The FASEB Journal 28: 60-68.

56. Bell MJ, Ternberg JL, Feigin RD, Keating JP, Marshall R, et al. (1978) Neonatal necrotizing enterocolitis. Therapeutic decisions based upon clinical staging. Ann Surg 187: 1-7.

57. Chan KY, Leung KT, Tam YH, Lam HS, Cheung HM et al. (2014) Genome-wide expression profiles of necrotizing enterocolitis versus spontaneous intestinal perforation in human intestinal tissues: dysregulation of functional pathways. Ann Surg 260: 1128-1137.

58. Stark AR, Carlo WA, Tyson JE, Papile LA, Wright LL, et al. (2001) Adverse effects of early dexamethasone in extremely-low-birth-weight infants. National Institute of Child Health and Human Development Neonatal Research Network. N Engl J Med 344: 95-101.

59. Attridge JT, Clark R, Walker MW, Gordon PV (2006) New insights into spontaneous intestinal perforation using a national data set: (1) SIP is associated with early indomethacin exposure. J Perinatol 26: 93-99.

60. Moss RL, Dimmitt RA, Barnhart DC, Sylvester KG, Brown RL, et al. (2006) Laparotomy versus peritoneal drainage for necrotizing enterocolitis and perforation. N Engl J Med 354: 2225-2234.

61. de Meij TG, van der Schee MP2, Berkhout DJ1, van de Velde ME1, Jansen AE1, et al. (2015) Early Detection of Necrotizing Enterocolitis by Fecal Volatile Organic Compounds Analysis. J Pediatr 167: 562-567.

62. Asmerom, Crowe, Marin (2015) Understanding the Biologic Therapies of Probiotics, Prebiotics, and Synbiotics: Exploring Current Evidence for Use in Premature Infants for the Prevention of Necrotizing Enterocolitis. J Perinat Neonatal Nurs 29: 240-247.

63. Berseth CL, Bisquera JA, Paje VU (2003) Prolonging small feeding volumes early in life decreases the incidence of necrotizing enterocolitis in very low birth weight infants. Pediatrics 111: 529-534.

64. Kamitsuka MD, Horton MK, Williams MA (2000) The incidence of necrotizing enterocolitis after introducing standardized feeding schedules for infants between 1250 and 2500 grams and less than 35 weeks of gestation. Pediatrics 105: 379-384.

65. Lin HC, Su BH, Chen AC, Lin TW, Tsai CH, et al. (2005) Oral probiotics reduce the incidence and severity of necrotizing enterocolitis in very low birth weight infants. Pediatrics 115: 1-4.

66. Bin-Nun A, Bromiker R, Wilschanski M, Kaplan M, Rudensky B, et al. (2005) Oral probiotics prevent necrotizing enterocolitis in very low birth weight neonates. J Pediatr 147: 192-196.

67. Lin HC, Hsu CH, Chen HL, Chung MY, Hsu JF, et al. (2008) Oral probiotics prevent necrotizing enterocolitis in very low birth weight preterm infants: a multicenter, randomized, controlled trial. Pediatrics 4: 693-700. 
Citation: Garg PM, Garg PP, Lal CV (2015) Necrotizing Enterocolitis (NEC): A Devastating Disease of Prematurity. J Neonatal Biol 4: 202. doi: 10.4172/2167-0897.1000202

Page 6 of 6

68. Gibson GR, McCartney AL (1998) Modification of the gut flora by dietary means. Biochem Soc Trans 26: 222-228.

69. Sherman PM, Cabana M, Gibson GR, Koletzko BV, Neu J, et al. (2009) Potential roles and clinical utility of prebiotics in newborns, infants, and children: proceedings from a global prebiotic summit meeting, New York City, June 27-28, 2008. J Pediatr 155: S61-70.

70. Underwood MA, Salzman NH, Bennett SH, Barman M, Mills DA, et al. (2009) A randomized placebo-controlled comparison of 2 prebiotic/ probiotic combinations in preterm infants: impact on weight gain, intestinal microbiota, and fecal short- chain fatty acids. J Pediatr Gastroenterol Nutr 2: 216-225.

71. Cotten CM, Taylor S, Stoll B, Goldberg RN, Hansen NI, et al. (2009) Prolonged duration of initial empirical antibiotic treatment is associated with increased rates of necrotizing enterocolitis and death for extremely low birth weight infants. Pediatrics 123: 58-66. 